RFP-1949

February 12, 1973

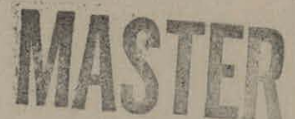

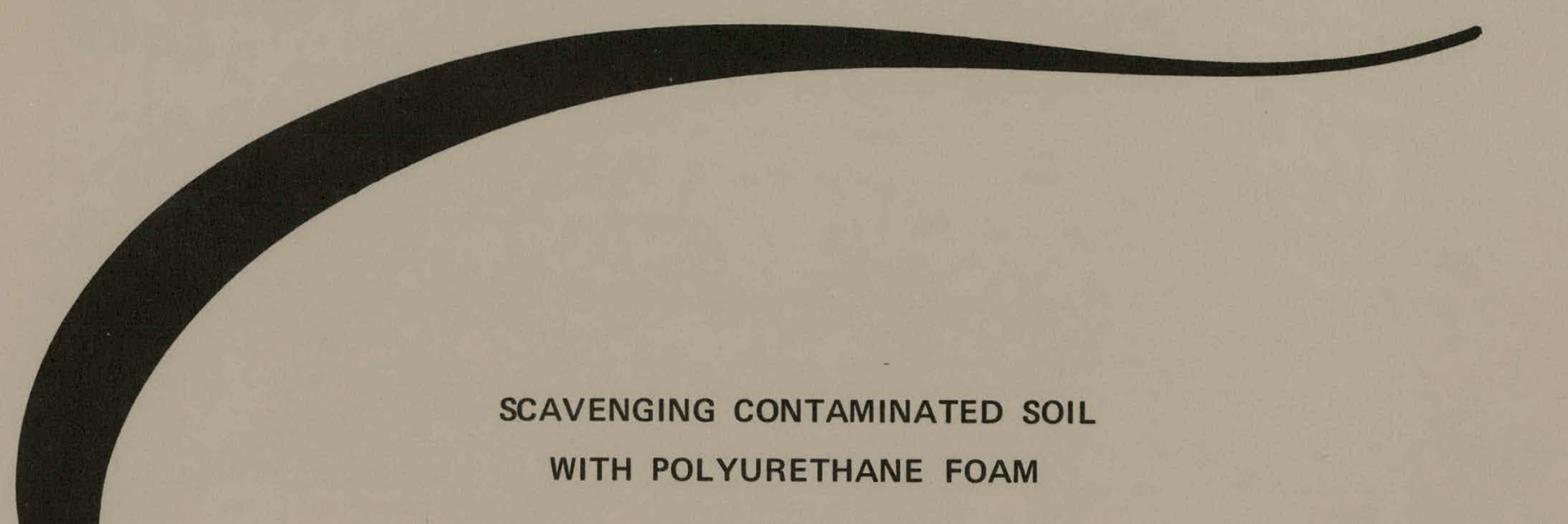

John W. Lindsay

Donald E. Michels

James A. Martinez

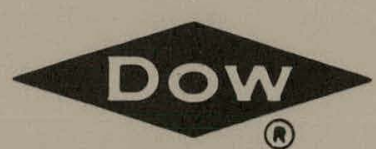

DOW CHEMICAL U.S.A. ROCKY FLATS DIVISION

P. O. BOX 888

GOLDEN, COLORADO 80401

U.S. ATOMIC ENERGY COMMISSION CONTRACT AT(29-1)-1106 


\section{DISCLAIMER}

This report was prepared as an account of work sponsored by an agency of the United States Government. Neither the United States Government nor any agency Thereof, nor any of their employees, makes any warranty, express or implied, or assumes any legal liability or responsibility for the accuracy, completeness, or usefulness of any information, apparatus, product, or process disclosed, or represents that its use would not infringe privately owned rights. Reference herein to any specific commercial product, process, or service by trade name, trademark, manufacturer, or otherwise does not necessarily constitute or imply its endorsement, recommendation, or favoring by the United States Government or any agency thereof. The views and opinions of authors expressed herein do not necessarily state or reflect those of the United States Government or any agency thereof. 


\section{DISCLAIMER}

Portions of this document may be illegible in electronic image products. Images are produced from the best available original document. 


\section{LEGAL NOTICE}

This report was prepared as an account of work sponsored by the United States Government. Neither the United States nor the United States Atomic Energy Commission, nor any of their employees, nor any of their contractors, subcontractors, or their employees, makes any warranty, expressed or implied, or assumes any legal liability or responsibility for the accuracy, completeness or usefulness of any information, apparatus, product or process disclosed, or represents that its use would not infringe privately owned rights.

Printed in the United States of America

Available from the

National Technical Information Service

II S Depatment of Commerce

Springfield, Virginia 22151

Price: Printed Copy $\$ 3.00$; Microfiche $\$ 0.95$ 


\title{
SCAVENGING CONTAMINATED SOIL WITH POLYURETHANE FOAM
}

John W. Lindsay

Donald E. Miche/s

James A. Martinez

\begin{abstract}
This report was prepared as an account of work sponsored by the United States Government. Neither the United States nor the United States Atomic Energy Commission, nor the United States Atomic Energy their contractors, subcontractors, or their employees, makes any warranty, cxpress or implied, or assumes any legal liability or responsibility for the accuracy, completeness or usefulness of any information; apparatus, product or process disclosed, or represents that its use would not infringe privately owned rights.
\end{abstract}

DOW CHEMICAL U.S.A. ROCKY FLATS DIVISION

P. O. BOX 888

GOLDEN, COLORADO 80401

Radioactive Contamination

Prepared under Contract AT(29-1)-1106 Soil Stabilizers

$$
\text { for the }
$$

Albuquerque Operations Offioo

U. S. Atomic Energy Commission 


\section{CONTENTS}

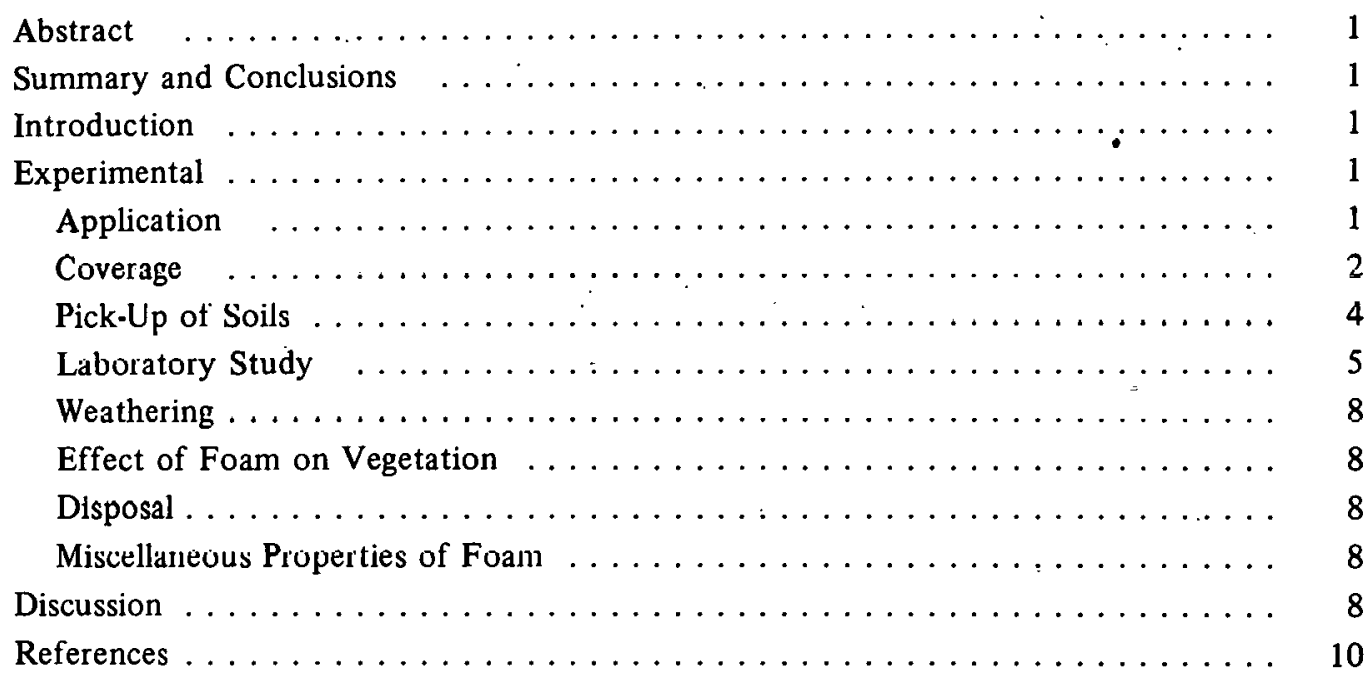




\title{
SCAVENGING CONTAMINATED SOIL WITH POLYURETHANE FOAM
}

\author{
John W. Lindsay, Donald E. Michels, and James A. Martinez
}

\begin{abstract}
Polyurethane foam has been evaluated as a stabilizing agent for radioactively contaminated soils. Results show that the foam can be applied efficiently to a wide variety of terrain and soils to form a lasting protective coating. In addition, the foam has a high capacity for picking up contamination, soil, and rocks, and has a relatively low cost. Its mechanical properties make handling and disposal easy. A laboratory procedure has been devised to measure quantitatively the ability of foams to pick up particulate materials by which comparisons between foams can be made.
\end{abstract}

\section{SUMMARY AND CONCLUSIONS}

The two-component foam was found to be readily applied by either of two systems. Test sites representing the types of soil and terrain at Rocky Flats were sprayed to determine rates of application necessary for different degrees of coverage, the durability of the covering, and the capabilities for picking up soil particles.

Rate of application of the foam on a flat-to-moderately inclined terrain varied from 5 - to 20 -square-feet per minute, depending on the amount of vegetation on the site. To cover soil containing vegetation required more time and more urethane foam than to cover bare soil. Watersaturated soil was also more difficult to cover than dry soil because a reaction occurs between water and one of the foam components.

I ifting of the hardened foam from the soil was done easily by either manual or mechanical means. Pick-up of sprayed soil was good because soil particles become encapsulated in the foam. Durability of the foam to weathering was excellent. Minor deterioration of the foam was noticeable after 10 months. Expected duration of unprotected foam is approximately 18 to 24 months. No adverse effects, other than smothering, were observed on vegetation.

Cost of the foam is comparable to an asphalt cover but no surface preparation is required prior to foaming. Expense and complexity of foam-laying equipment is considerably less than for other kinds of durable coverings. Application of a 2-in.-thick coating of foam, which adequately stabilizes the soil and is optimum for handling during disposal, requires 34 pounds per 100 square feet for relatively flat surfaces. Cost of material is about $\$ 22.50$ per 100 square feet.

\section{INTRODUCTION}

Facilities which handle radioactive elements are responsible for preventing contamination of the environment. Such a responsiblility is being met to the fullest extent possible. For example, recent emphasis on improved physical plants and handling techniques will minimize the release of contaminants. Still, contingency plans must be devised for lessening the environmental impact of any accidental release.

Following the release of a radioactive material to the outdoors, the first action is to prevent the spread of contaminant to surrounding areas. Quickness of action is important because of the possible rapid dispersion of the contaminants by weather.

Direct lifting of the affected soil ${ }^{1}$ is an immediate solution but risks further spreading of the contamination, especially during high winds or rain. Polyurethane foam is an agent which will cover the contaminated surface and contain the contaminant until better conditions are available for its pick-up. Polyurethane foam has several advantages: First, and most important, it forms an adherent protective barrier on a wide variety of substrates; Second, techniques for applying the foam give a quick, efficient operation over a wide range of weather and topographical conditions; Third, once applied, the foam resists environmental decay, giving time for other decontamination operations to be arranged or completed; Fourth, the foam encapsulates contaminated rocks, soil, and vegetation, and the composite can be lifted cleanly and intact from the site.

This report describes efforts by the Rocky Flats Environmental Research group to develop an emergency soil stabilization system. The objective is to rapidly contain and easily decontaminate a radioactively dosed area of soil. This report deals only with polyurethane foams. Other agents have been studied previously. ${ }^{2,3}$

\section{EXPERIMENTAL}

\section{Application}

Two commercially available foaming units were evaluated for their ability to deliver a uniform 2-in.-thick layer of foam on soil. The first involved an air-driven pump 
transfer unit (DeVilbiss Corporation, Toledo, Ohio). The complete system was mounted in a $1 \frac{1}{2}$-ton truck which gave good mobility over many terrains. Air for operating the unit was provided by an air compressor $(40 \mathrm{cfm}$, two-stage) mounted on a trailer pulled by the truck. Fifty feet of hose, coupled with the mobility of the mounted unit, provided a capability for covering most of the rollinghill terrain at Rocky Flats. Temperature control for the two 55-gallon urethane source drums (two-component system) at 60 to $70^{\circ} \mathrm{F}$, and for the delivery hose at $120^{\circ} \mathrm{F}$, was maintained by electrical resistance heaters connected to a gasoline-powered generator also mounted on the truck.

Delivery rate of the foam (density $2 \mathrm{lb} / \mathrm{ft}^{3}$ ) used in these tests was between 15- and 20-1b per minute (Figure 1). The pattern of spray given by the gun was sufficient for making a uniform 2-in.-thick layer of foam on a flat surface.

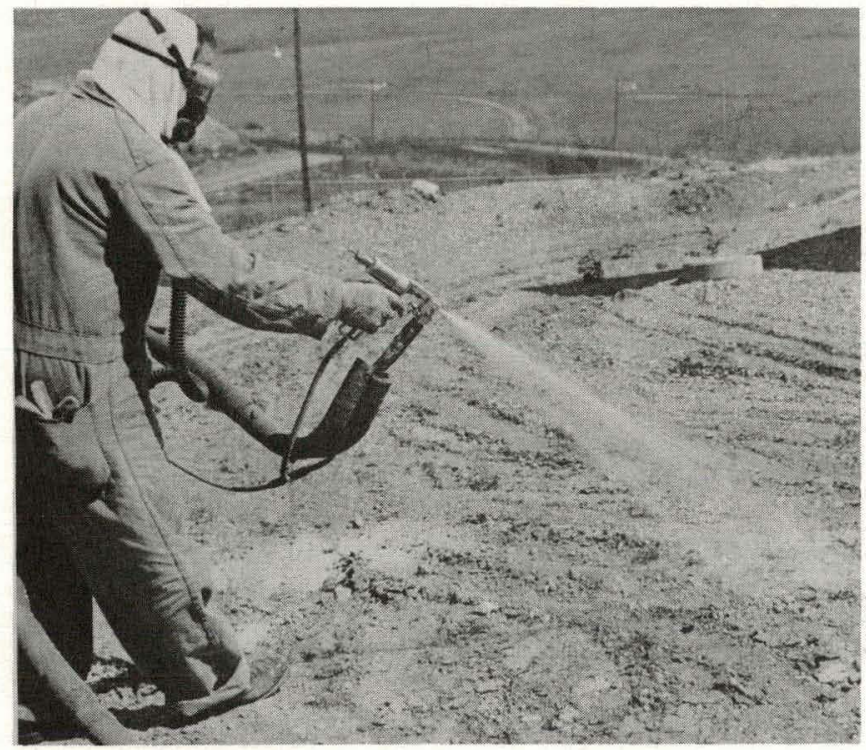

Figure 1. Application of Foam with Pump Transfer System.

The rate of surface coverage was $12-\mathrm{ft}^{2}$ per minute. The unit was not particularly reliable. Frequently, delays in start-up of the complex system were caused by fouling in pumps and transfer lines.

The second spray unit tested was a pressurized foam transfer system (MR Plastics and Coatings, St. Louis, Missouri). The system consists of two tanks each holding 50 pounds of components, a 240-cubic-foot nitrogen tank, 25 feet of delivery hose, and a mixing-head gun. The entire unit was mounted on a cart 3-feet square. The unit can be mounted in a truck, and is small enough to be man-handled in difficult terrain. This system utilizes compressed nitrogen to drive the components through the hoses, to mix the components, and to disperse the foam.
Delivery rate of foam $\left(2 \mathrm{lb} / \mathrm{ft}^{3}\right)$ was approximately 15 -lb per minute. Nitrogen comsumption for rapid spraying was approximately 17 -cubic-feet per minute. Delivery from the gun was sufficient to apply a 2 -in.-thick layer of foam to a flat substrate at a rate of $10-$ to $20-\mathrm{ft}^{2}$ per minute.

Reliability of the unit was excellent when adequate rinsing of the gun followed each use. Vibrating the pressurized source tanks for 20 to 30 minutes before drawing from them improved the delivery of a good foam.

\section{Coverage}

Three parameters were considered in choosing test sites: soil type, vegetation, and surface condition of the soil. Figures 2, 3, and 4 show threc sites (each 150 squarc foct) chosen for the tests. Site A (Figure 2) is a gravel fill; flat, and without vegetation. This site is typical both of areas next to roads and of areas between buildings at Rocky Flats. The DeVilbiss system was used to apply a uniform 2-in.-thick layer of foam to Site A (Figure 5). The machinery functioned satisfactorily. Weather conditions during application were hot and windy; $85^{\circ} \mathrm{F}$ and a $30 \mathrm{mph}$ wind. Prior to spraying, two sections (see Figure 2) were respectively saturated with an oil-carbon tetrachloride mixture and with water to determine their effects on production and adherence to the foam.

Coverage of the dry segment of the site was done at a rate estimated to be 15 - to 20 -square-feet per minute. Total coverage was obtained in two passes of the gun.

Figure 2. Site A Prior to Spraying.

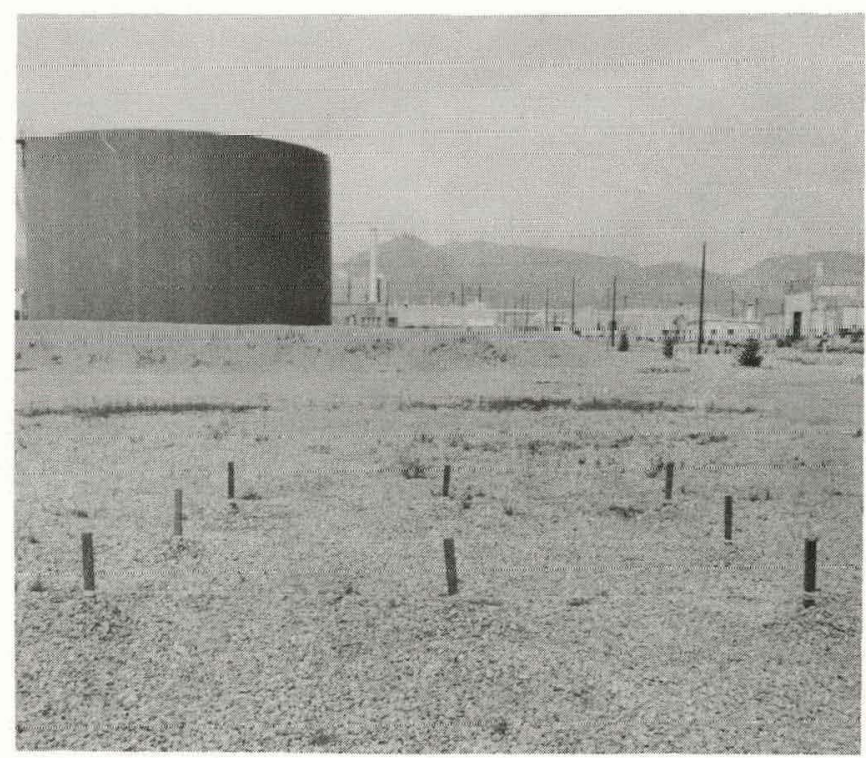




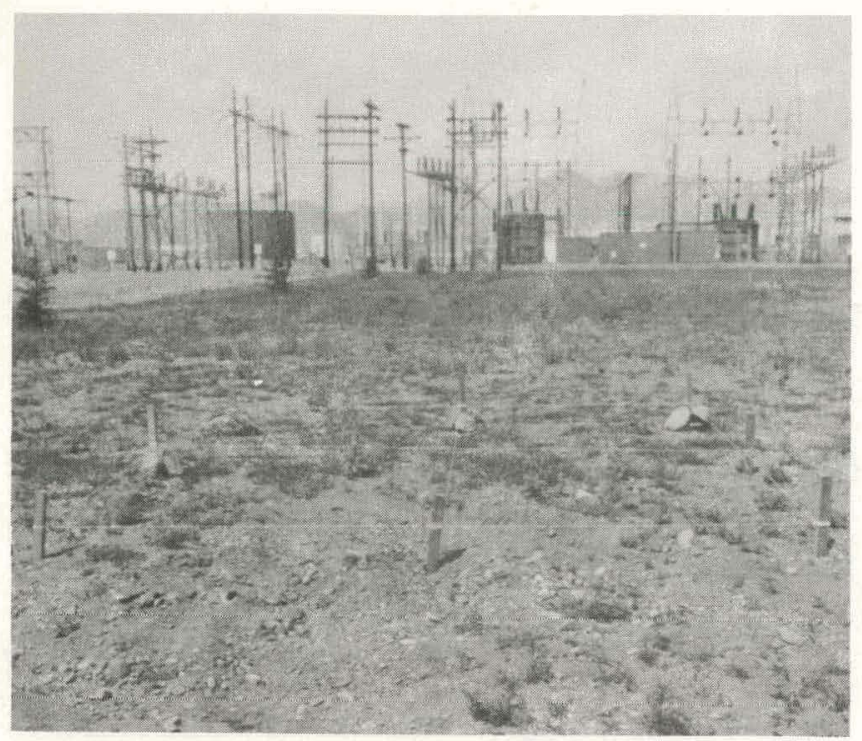

Figure 3. Site B Prior to Spraying.

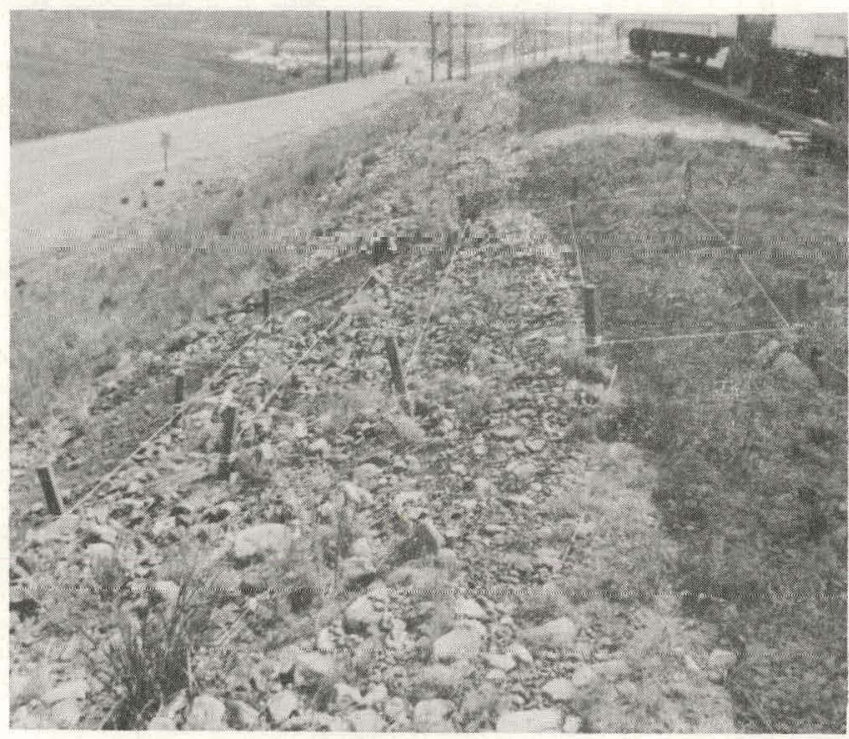

Figure 4. Site C Prior to Spraying.

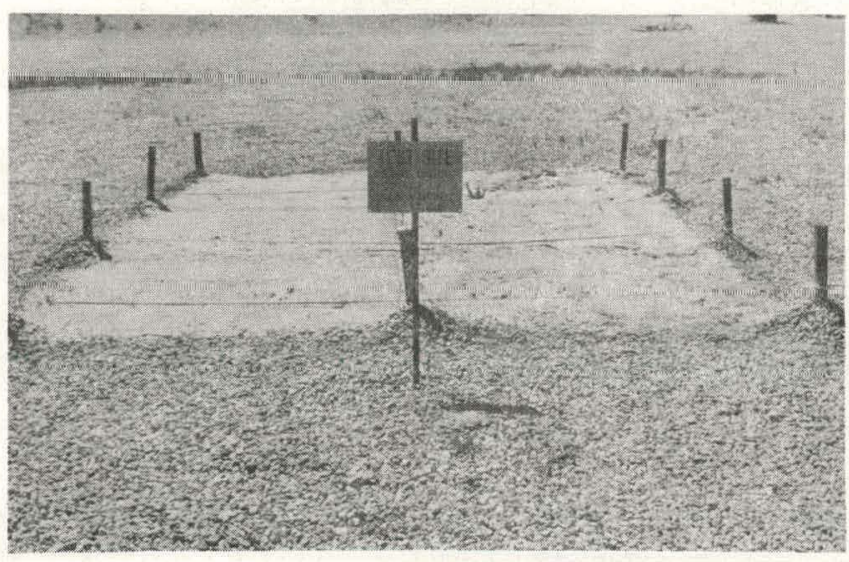

Figure 5. Site A Following Spraying.
In the oil-carbon tetrachloride saturated portion, three or four passes were found necessary to yield a uniform 2-in.-thick layer. Rate of covering was estimated at about 10-square-feet per minute.

Covering the water-saturated portion was difficult because the isocyanate component of the foam reacts with water. Good coverage was delivered, however, with five or six passes of the gun. Covering rate of the wet surface was approximately 5-square-feet per minute.

Coverage of a similar 150-square-foot site adjacent to Site A was done with the MR Plastics system. Results were similar to those obtained with the DeVilbiss unit.

The second site chosen for test spraying (Site B, Figure 3) represents a soil-gravel surface composition common at Rocky Flats. Boulders range in size up to 8 inches. Vegetation at Site B was sparce. Covering Site B (Figure 6) with foam was done in a manner similar to that used at Site A, although the vegetation required special attention. Unidirectional spraying of taller plants resulted in a shadowing effect which caused incomplete coverage. Full coverage was effected by spraying in two diagonal directions.



Figure 6. Site B Following Spraying.

The vegetated area was covered at a rate of about 10-squarefeet per minute. Weather conditions at the time of application were hot and windy; similar to the conditions when spraying Site A.

The third test site (Site C, Figure 4) possesses a surface similar to the undisturbed soil at Rocky Flats. In addition, the surface is inclined at $35^{\circ}$. Vegetation consisted of thick grass on about $10 \%$ of the test site. Covering of the site (Figure 7) with foam was easily accomplished, using an inclined $\left(\sim 45^{\circ}\right)$ gun position. Weather conditions were hot and windy as at Sites B and A. 


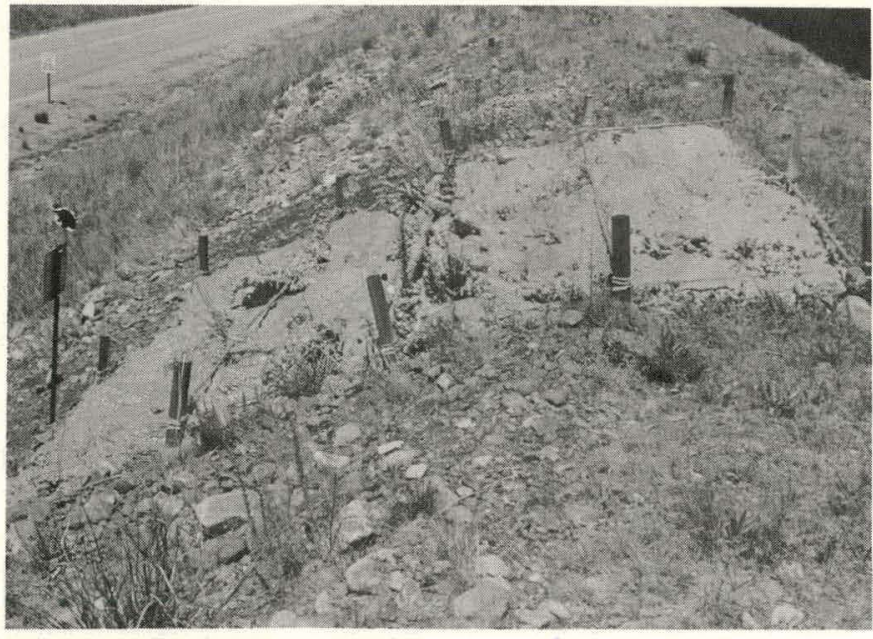

Figure 7. Site C Following Spraying.

\section{Pick-Up of Soils}

Figures 8 and 9 show sections of foam removed from the area of Site A which was dry at the time of spraying.

All sizes of particles touched by the foam were bound tightly enough to be picked up. The largest stone was 3 -inches long. Foams sprayed on the wetted surfaces are shown in Figures 10,11, 12, and 13, respectively. Pick-up of the water-wetted soil was meager. Pick-up of the soil wet by the oil-carbon tetrachloride mixture was only slightly less than for the dry soil.

Figure 8. Section of roam and Soil Removed from Dry Segment of Site A.
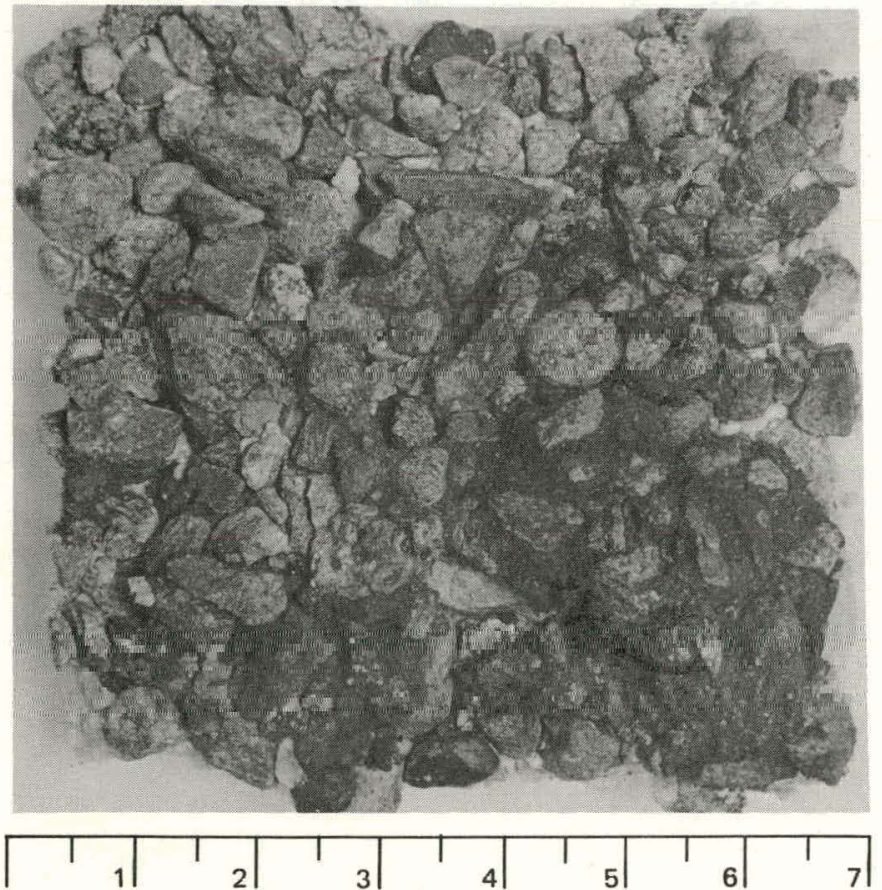
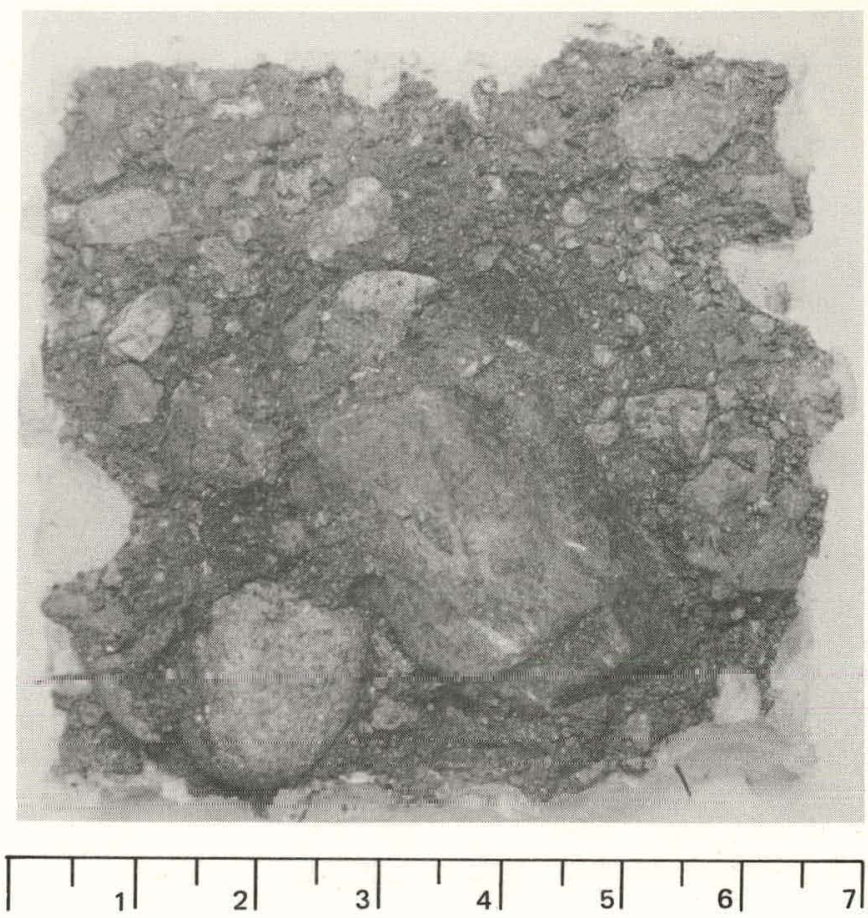

Figure 9. Section of Foam and Soil Removed from Dry Segment of Site A.
Figure 10. Section of Foam and Soil Removed from Oil-CCl Wetted Segment of Site A.

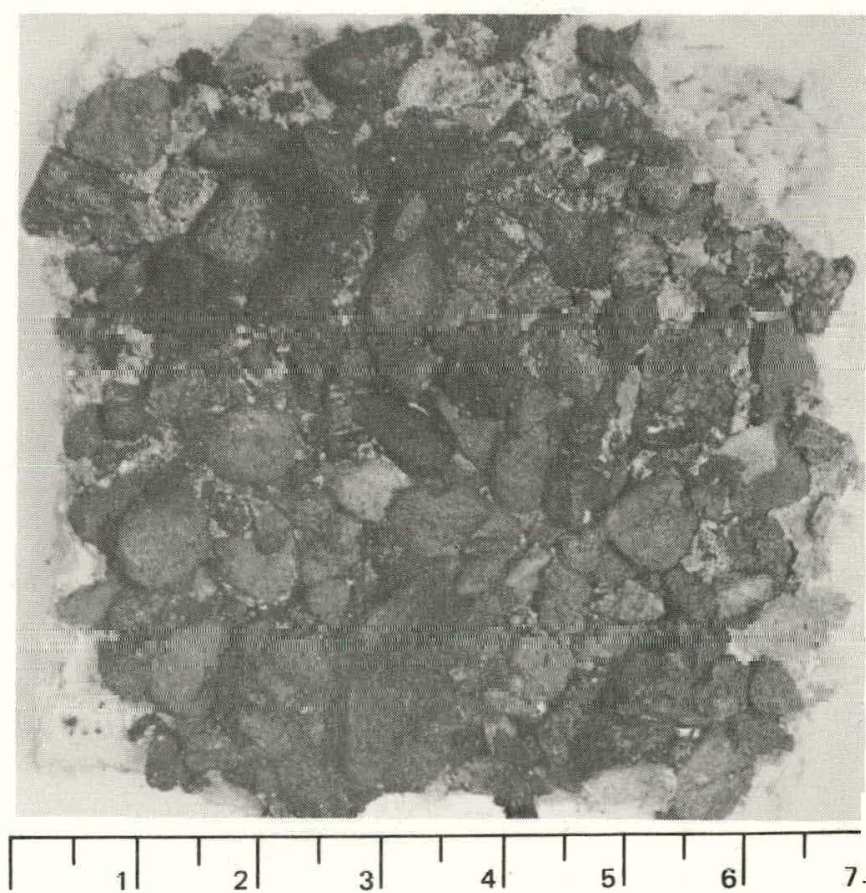



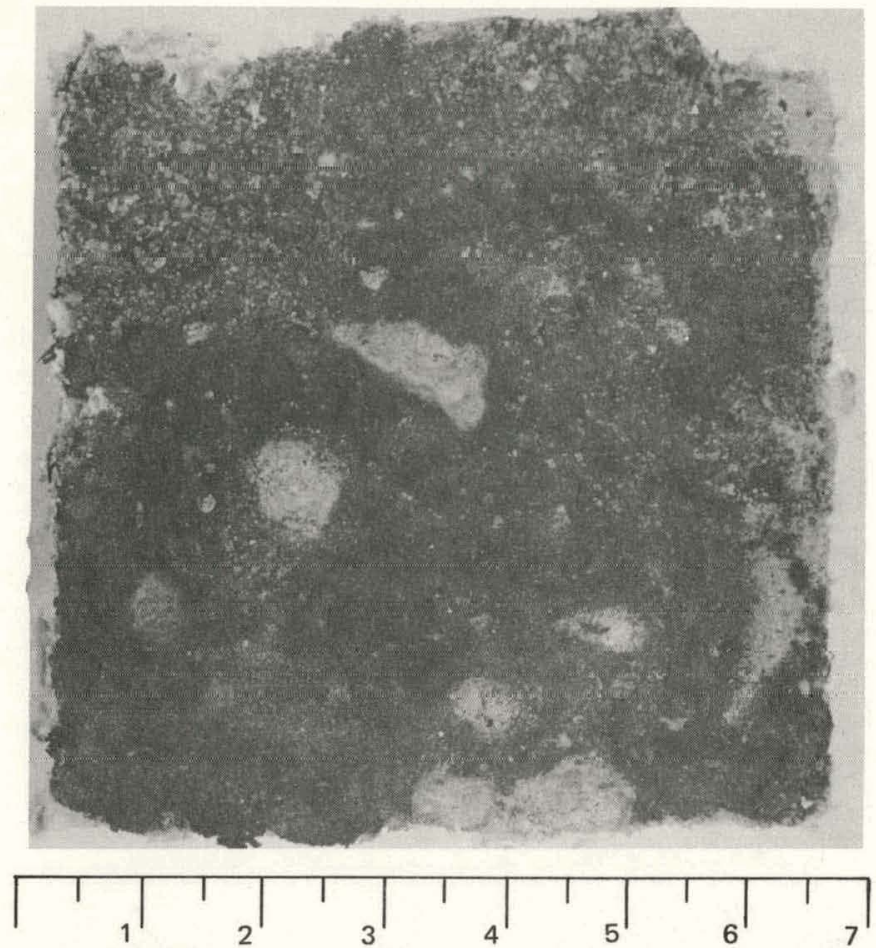

Figure 11. Section of Foam and Soil Removed from Oil- $\mathrm{CCl}_{4}$ Wetted Segment of Site A.

Figure 12. Section of Foam and Soil Removed from Water Wetted Segment of Sitc A.
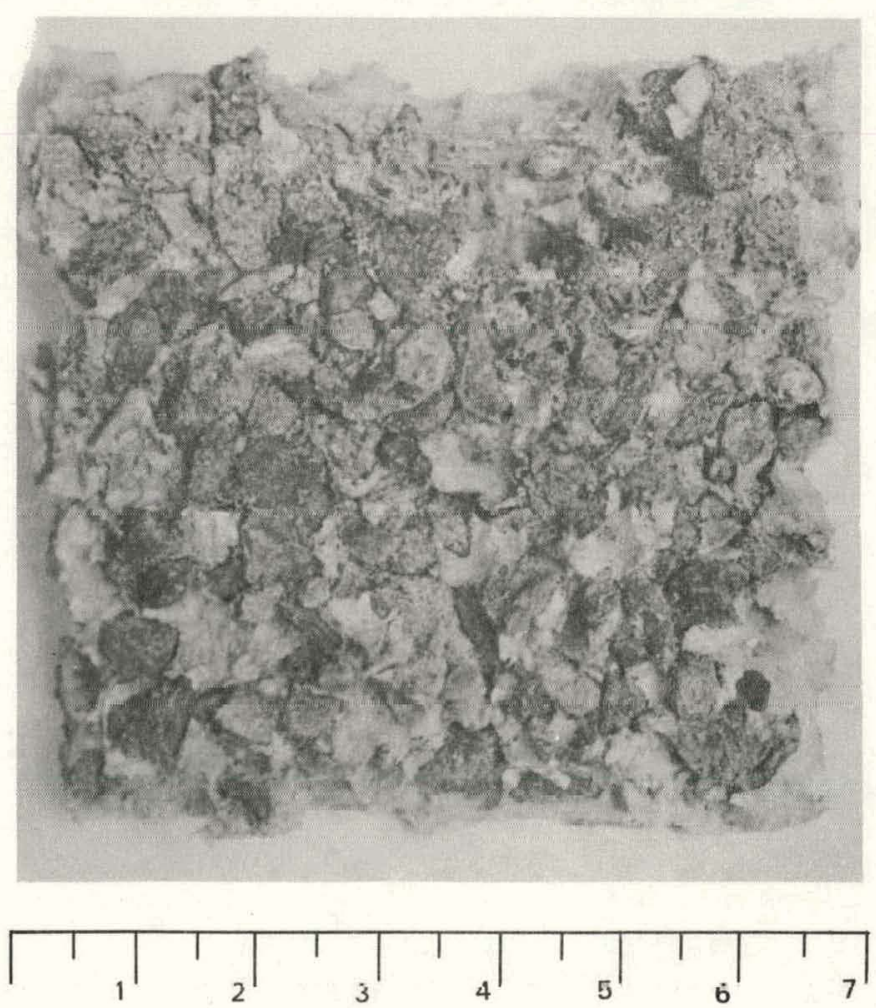
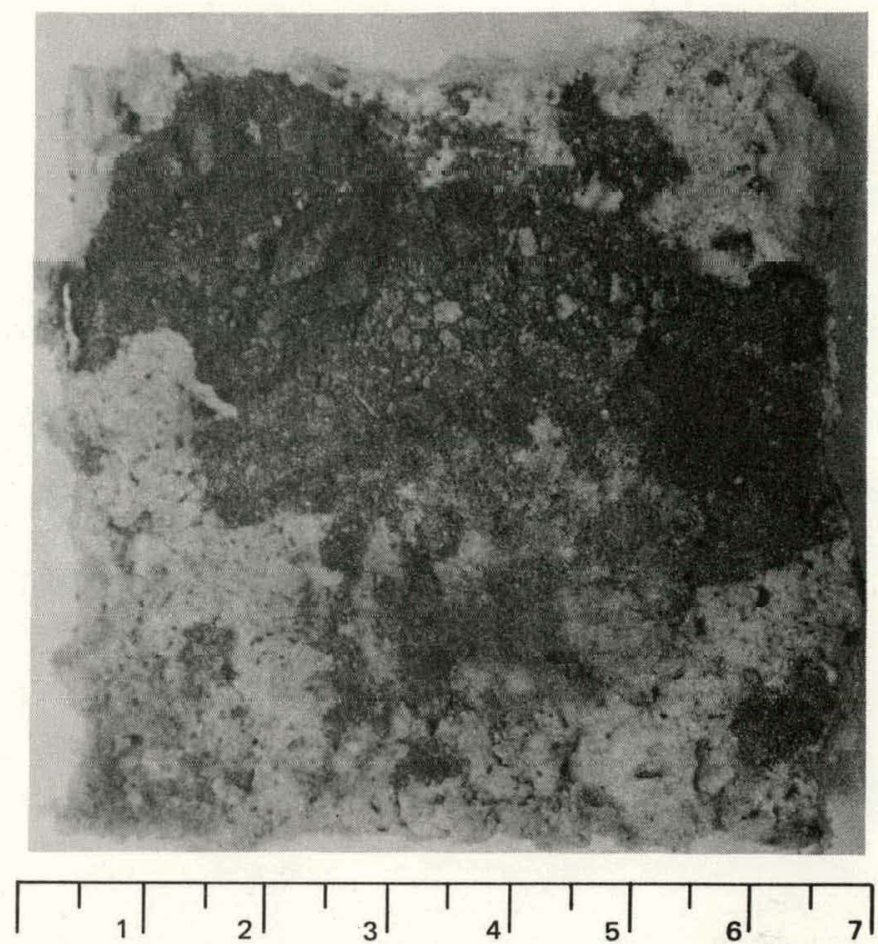

Figure 13. Section of Foam and Soil Removed from Water Wetted Segment of Site A.

\section{Laboratory Study}

To quantify the relationships between foam and soil particles, a laboratory study was made relative to different sizes of sand particles. The principal value of this section is to describe a technique for comparing the performance of different foams. The sands used were essentially of granite composition, and sieved to yield seven fractions that differed in mean diameter by factors of two over the range 0.062 to 4.0 millimeters. Table 1 shows the sieve openings used, and the mean particle sizes of the separate fractions.

Table 1. Size Range and Mean Sizes of Test Stands.

Sieve Opening $(\mathrm{mm})$

\subsection{1}

2.79

1.40

0.701

0.315

0.175

0.088

0.043
Nominal Mean Size of Retained Fraction ( $\mathrm{mm}$ )
4.0

2.0

1.0

0.5

0.25

0.12

0.062 
Mineralogical differences occurred among the size fractions. The 1- and 4-mm fractions contained abundant dark minerals such as biolite and hornblend. Many of the particles were multi-mineralic. The 1.0 - and $0.5-\mathrm{mm}$ fractions contained large percentages of quartz and feldspar with some multi-mineralic particles. The lower fractions were dominated by quartz.

Pick up of the various fractions was quantified on the basis of mass, volume, and area. Preweighed amounts of sand were placed in 4-in.-diameter petri dishes and covered with foam. The amount picked up was indicated by weight loss of the loose sand remaining after the foam was removed from the dish. Basic data are in units of grams of sand picked up per square centimeter but this must be converted to an area and volume basis to make comparisons. These techniques can be extended to test the effects of temperature, moisture content, etc. on the adherence of foam to sand.

Table 2 shows the data obtained from the foaming of various size fractions of dry sand at $72^{\circ} \mathrm{F}$. Bulk densities of the fractions were measured separately.

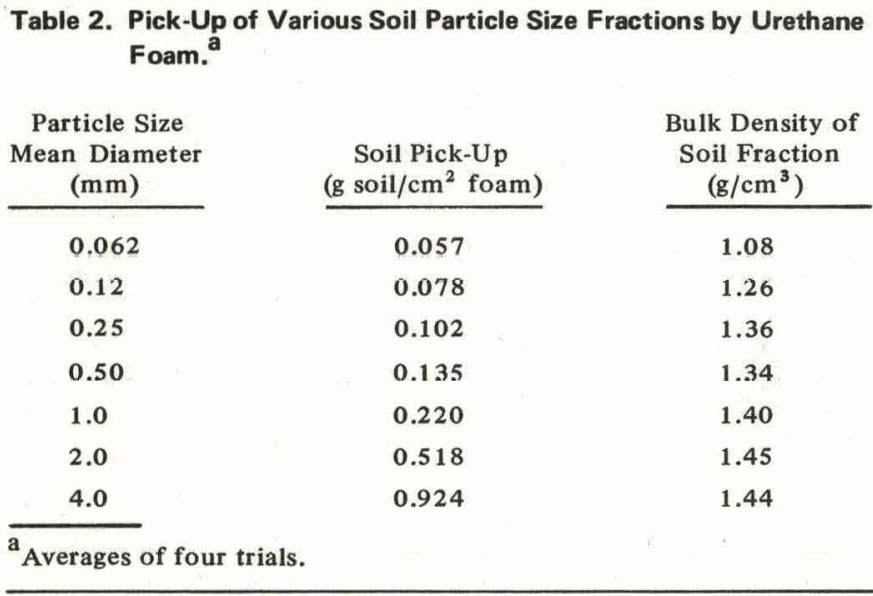

Assuming the number of layers of the sand particles picked up by the foam is given by equation 1.a and the depth of the portion removed is given by equation 1.b.

$$
\begin{aligned}
& \text { Number of layers lifted }=\frac{\mathrm{g} / \mathrm{cm}^{2}}{\mathrm{Da}} \\
& \text { Depth of soil lifted }=\frac{\mathrm{g} / \mathrm{cm}^{2}}{a}
\end{aligned}
$$

where: $\mathrm{g} / \mathrm{cm}^{2}=$ grams soil per square centimeter

D = mean diameter of particle in soil fraction

$a \quad=$ bulk density of soil fraction
The number of layers and the soil depth lifted were calculated. Results are given in Table 3. The large number of layers of smaller particles picked up by the foam is impressive. The number may reflect turbulences at the interface which could be exploited when more effective foams are to be designed.

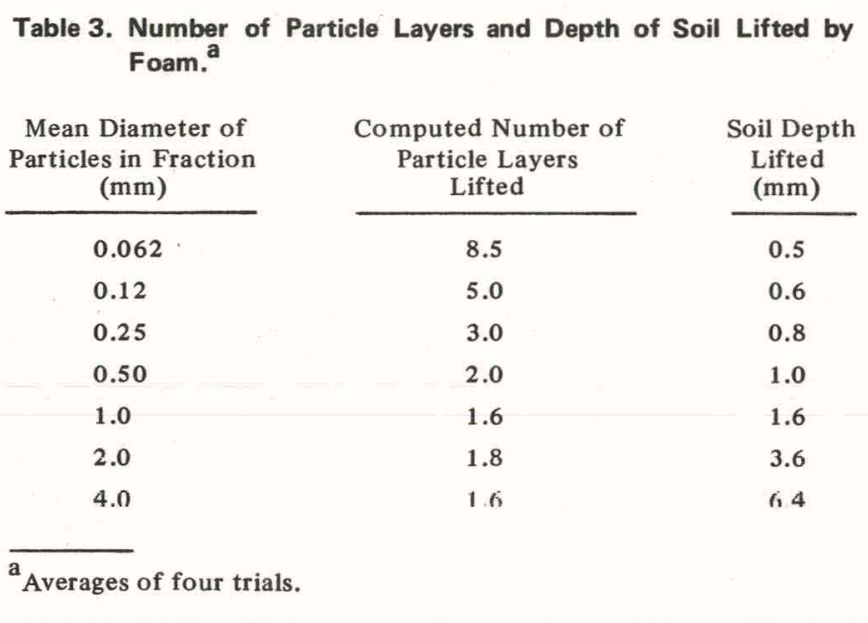

Pick up of three-component mixtures of particle sizes was done to find whether data like those in Table 3 can be used to predict how a foam will respond to a mixture of particle sizes as occurs in real soils. After a portion of the mixture was picked up by the foam, the remainder was sieved so the individual components could be re-weighed and the weight losses calculated.

Composition of the portion picked up by the foam was indicated by differences in weight. Results are shown in Table 4. The simplest mudel for the pick-up of mixed sizes of particles assumes that the affinity between particles and foam is the same whether the particle is tested alone or in a mixture.

By implication, the model assumes that the amount of any component picked up is proportional to that area of the 74- $\mathrm{cm}^{2}$ petri dish which is occupied by the component. In an ideal mixture the distribution of particles in a plane through the mixture (such as the exposed surface) is numerically the same as the distribution of volumes of the component particles. Equations 2.a and 2.b relate the volumes and masses of the components to the area of foam. The computed values can then be compared with the experimental ones. Table 4 shows the calculated and actual pick-ups of mixtures. Agreement is qualitative, although pick-up of the intermediate size fraction is poorly predicted. Since fine particles can occupy space between coarse particles the volume of different sized components are not additive and the agreement between computed and measured values in Table 4 seem surprisingly good. 
RFP-1949

Table 4. Actual and Calculated Pick-Ups of Three-Component Mixtures.

Soil Fraction in Composite

$(\mathrm{mm})$

2.0

0.50

0.12

2.0

0.50

0.12

2.0

0.50

0.12

2.0

0.50

0.12

2.0

0.50

0.12

2.0

0.50

0.12
Mass Fraction in Composite

$$
0.50
$$

0.30

0.20

0.20

0.30

0.50

0.15

0.30

0.55

0.33

0.33

0.33

0.10

0.30

0.60

0.05

0.30

0.65

$\begin{aligned} & \text { Volume fraction } \\ & \text { of component } i\end{aligned}=V_{i}=\frac{m_{i} / a_{i}}{\frac{m_{i}}{\sigma_{i}}+\frac{m_{j}}{\sigma_{j}}+\frac{m_{k}}{\sigma_{k}}}$

Calculated grams of

$\begin{aligned} & \text { component i picked up } \\ & \text { from } 74 \mathrm{~cm}^{2} \text { surface }\end{aligned}=\left(74 \mathrm{~cm}^{2}\right)\left(\mathrm{V}_{\mathrm{i}}\right)\left(\mathrm{L}_{\mathrm{i}}\right)$

area test surface

where: $m_{i}=$ mass fraction in composite

$a_{\mathrm{i}}=$ bulk density

$\mathrm{L}_{\mathrm{i}}=$ grams of component per square centimeter when particles are

lifted from single component system.

Effects of moisture and temperature (not simultaneously) on the pick-up of single-size fractions also were determined by foaming sand in petri dishes. Pick-up of both sand conditioned to $32^{\circ} \mathrm{F}$ before foaming and also of sand saturated with water is shown in Figure 14. Pick-up of wetted sand was erratic. Pads of foam sprayed on wetted sand developed vertical pipes which carried some sand, but left a void between the sand and the foam. Apparently this occurred when the isocyanate component reacted with wateı. Tlie effect was greater with the smaller particle stzes.
Volume Fraction in Composite

\begin{tabular}{|c|c|}
\hline $\begin{array}{l}\text { Calculated Pick-Up } \\
\text { (g) }\end{array}$ & $\begin{array}{l}\text { Actual Pick-Up } \\
\text { (g) }\end{array}$ \\
\hline 18.1 & 23.5 \\
\hline 3.1 & 7.8 \\
\hline 1.3 & - \\
\hline 7.0 & 7.8 \\
\hline 3.0 & 3.8 \\
\hline 3.0 & 3.8 \\
\hline 5.2 & 4.8 \\
\hline 2.9 & 5.3 \\
\hline 3.3 & 4.2 \\
\hline 12.0 & 13.1 \\
\hline 13.3 & 9.4 \\
\hline 2.1 & 2.8 \\
\hline 3.4 & 3.5 \\
\hline 2.9 & 5.5 \\
\hline 3.6 & 3.6 \\
\hline 1.7 & 1.6 \\
\hline 2.9 & 6.0 \\
\hline 3.9 & 5.8 \\
\hline
\end{tabular}

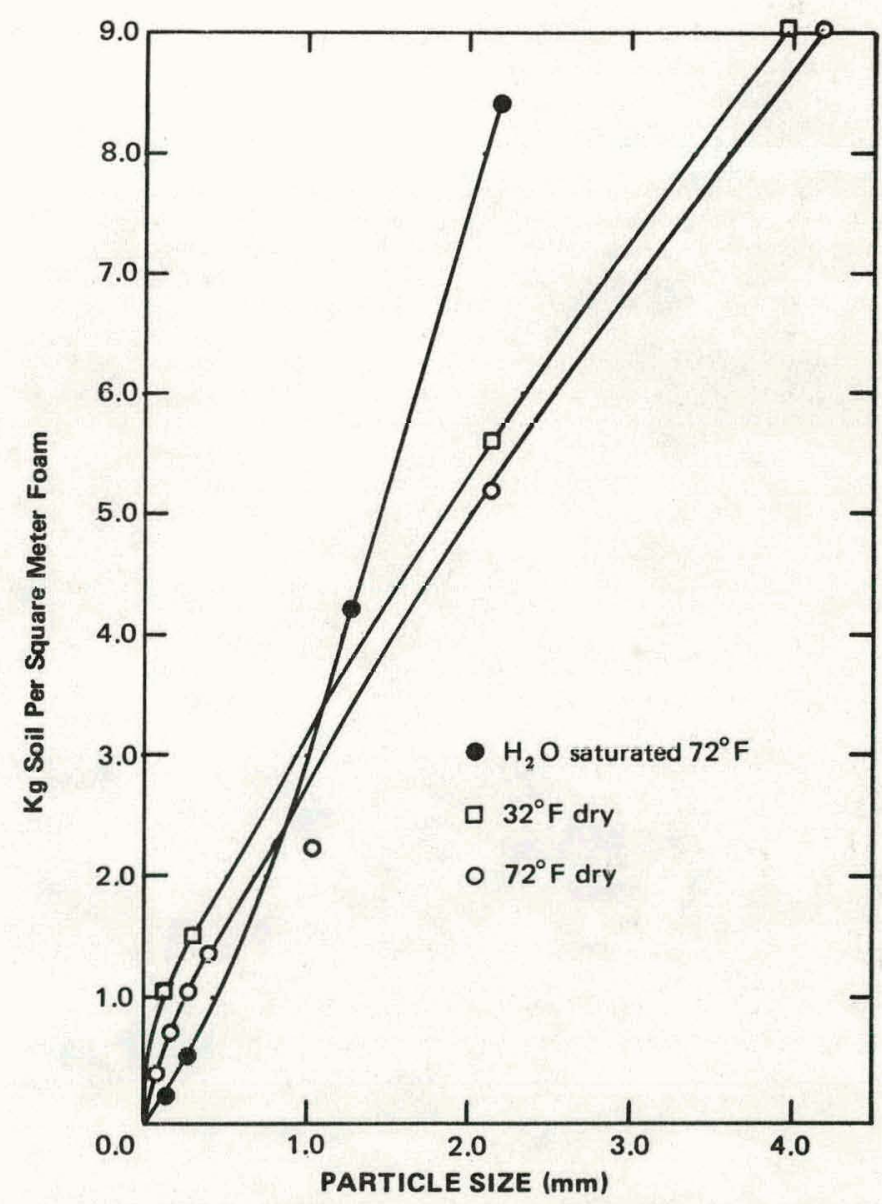

Figure 14. Effect of Water and Cold on Foam Pick-Up of Sized Soil Fractions. 
The lower temperature enhanced the pick-up of all sizes of sand. Foaming procedures required the foam constituents to be mixed and poured at $72^{\circ} \mathrm{F}$ so that chilling occurs only to the first increment of foam which touches the sand. That chilled increment eventually foams, but seeps deeper into the sand layer than unchilled foam. Therefore, a thicker section of sand becomes encapsulated in cooler foam. Improved performance foams could exploit the advantage of greater penetration before foaming.

\section{Weathering}

Figures 15 and 16 show Sites A and C, respectively, after 10 months of weathering (June through March ). Loaf-like decorations on the foam are foam patches applied to places where samples were cut from the original foam layer.

During that time, temperatures varied from a high of $100^{\circ} \mathrm{F}$ to a low of $-20^{\circ} \mathrm{F}$. Moisture from rain and snow amounted to approximately $10 \mathrm{in}$. and gusts of wind occurred that exceeded $100 \mathrm{mph}$. Except for small areas

Figure 15. Site $A$ after 10 Months.

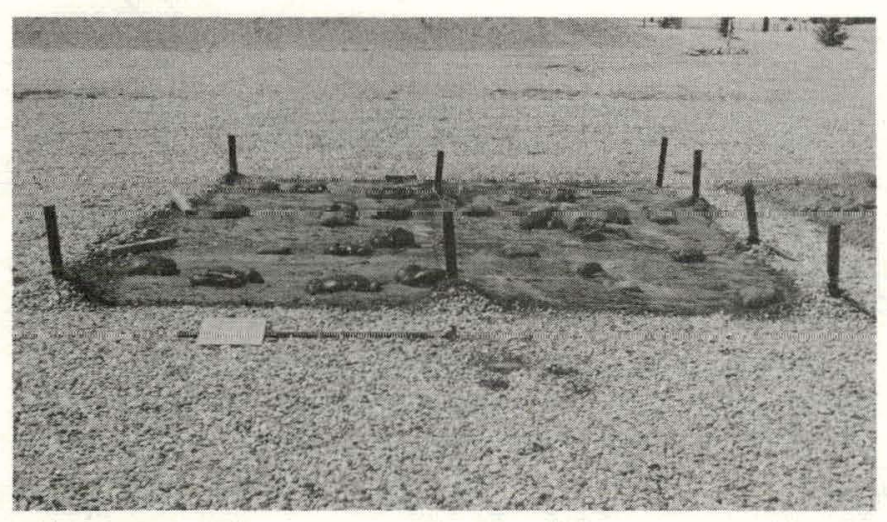

Figure 16. Site $\mathrm{C}$ after 10 Months.

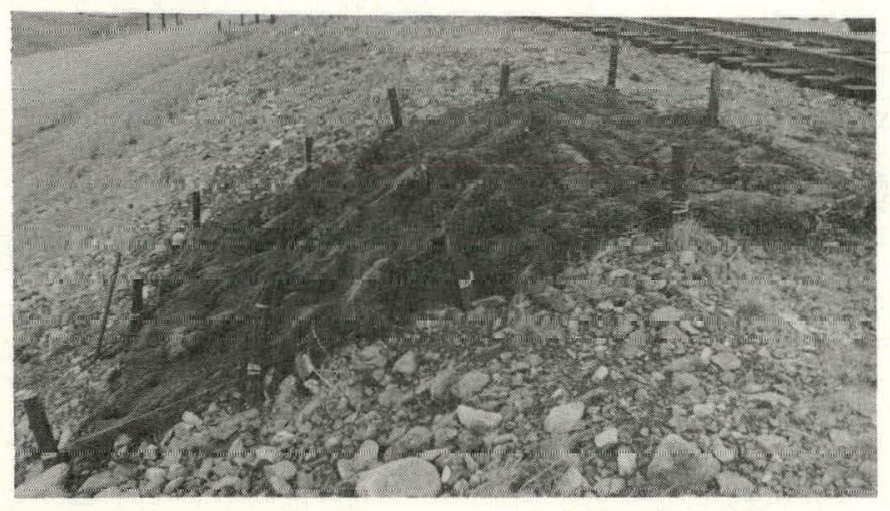

pierced by new vegetation growing during the spring season, the basic physical integrity of the foam was maintained throughout the exposure. Minor erosion of the foam resulted from wind-driven sand. Sunlight (ultra violet) induced chemical degradation. Thickness of the foam had decreased about one inch; to about half the thickness originally present.

\section{Effect of Foam on Vegetation}

Plants which were covered totally by the foam during * spraying were killed. Plants which were only partially covered survived, and even flourished; showing increased growth rates relative to surrounding plants.

Spring growth of new plants (from seeds that had been dormant the previous year) penetrated foam at all sites $\mathrm{A}, \mathrm{B}$, and $\mathrm{C}$.

\section{Disposal}

Lifting of foam from Site A was done casily either by hand or with a front-end loader (Figure 17). Hand lifting was best done after cutting the foam to the desired sizes with a blade.

Disposal of the foam is best accomplished by incineration. Thermal analyses of the foam heated in air show a residual carbon deposit of approximately $20 \%$ of the initial weight of the foam (upon heating to $700^{\circ} \mathrm{C}$ at $10^{\circ} \mathrm{C}$ per minute).

\section{Miscellaneous Properties of Foam}

Foam used in the testing was a two-component formulation produced by Dow Chemical U.S.A. and marketed under the name of Mistafoam $®, \mathrm{~S}-802 \mathrm{D} / \mathrm{H}-800-\mathrm{K}$. Properties as supplied by the manufacturer are given in Table 5 .

\section{DISCUSSION}

Polyurethanc foam has many of the attributes needed in a stabilizing agent applied to contaminated soil. Methods of applying the foam lend themselves to a mobile operation. Particularly, the dispenser powored by compressed nitrogen is well-suited for a mobile emergency system. Because of its lack of moving parts and simplicity, rellability of the system is improved over pump transfer units.

Additiunal nivodifications can improve the reliability of the foaming unit as required for emergency use. Quick release 


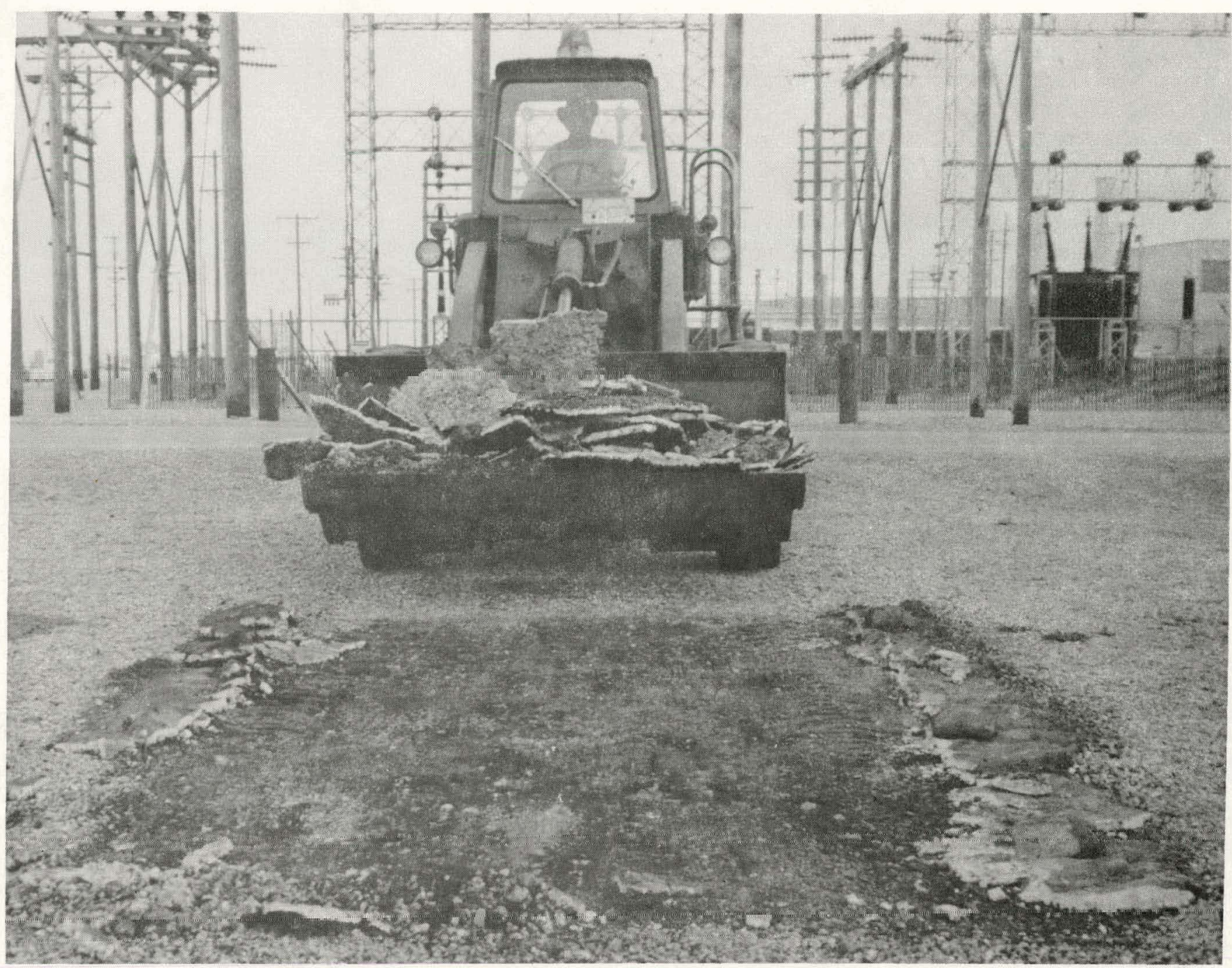

Figure 17. Removal of Site A Foam with Front-end Loader.

Table 5. Mistafoam ® Properties.

Density: $1.9 \mathrm{lb} / \mathrm{ft}^{3}$

Compressive Strength $-10 \%$ deflection:

parallel to rise direction $-40 \mathrm{psi}$

perpendicular to rise direction -25 psi

Compressive Modulus: 350

Ultimate Tensile Strength: $46 \mathrm{psi}$

Flame Resistance: ASTMD-1691 - Self-extinguishing

Rise Time: 3 to 4 minutes

Moisture Penetration: 1 to 3 per inch

Foam is durable enough to withstand damage from light foot traffic.

couplings and in-line filters are needed to prevent line plugging. The couplings provide a means to rapidly exchange empty tanks or a plugged gun head. Optimum gas flow for producing an efficient spray pattern from the unit appears to be about 15 to $20 \mathrm{cfm}$. Since this flow rapidly drains a 240 -cfm-nitrogen tank, a compressed air service would be desirable. Moisture in ordinary air cannot be permitted inside the tanks of foam components because of the water-isocyanate reaction. Bottled gas (nitrogen) must in any case be used to drive the fluids from the tanks and for mixing it. The air source would be used only for projecting the foam. Ease of covering a given area will vary with the amount of vegetation and with the moisture residing at the surface to be covered. Normal coverage of a sparsely vegetated soil can be accomplished at rates of up to $20 \mathrm{ft}^{2}$ per minute. Tall vegetation may cut this rate to as low as $5 \mathrm{ft}^{2}$ per minute. Soil saturated with water will also reduce the rate of application but will not prevent the formation of a layer adequate to resist weather.

Effect of freezing temperatures on foam formation would not appear to be severe providing the components are 
maintained between 60 and $70^{\circ} \mathrm{F}$. Cause for increased pick-up from the $32^{\circ} \mathrm{F}$ soil can be attributed to a slower degree of foaming and hence better penetration of the soil by the foam. Long-term (normally one year) protection of a contaminated surface appears good. Primary sources of degradation appear to be from solar ultra-violet radiation. Coating for the foams which are impermeable to ultraviolet radiation are available and could extend the life of a foam cover. The foam-coated test sites could likely have remained intact for an additional 8 to 14 months beyond the 10 -month period studied.

Effects on vegetation are minor. Only those plants covered totally by the foam were killed. Presumably, smothering rather than toxicity of the foam was responsible since partially sprayed plants continued to thrive.

In one instance of real contamination at Rocky Flats, polyurethane foam was used to stabilize and pick up the contamination. Contamination then was limited to about
4 square meters of ground similar to Site B. Surface contamination ranged upward to 0.6 millicuries per square meter. About $85 \%$ of the activity was removed by a single application of polyurethane foam 2-inches deep over the soil. No further spread of contamination occurred during the cleanup.

\section{REFERENCES}

1. R. G. Menzel and P. E. James, "Removal of Radioactive Fallout from Farm Land," Agricultural Engineering. (1971)

2. D. D. Hornbacher, Rocky Flats Division, Dow Chemical U.S.A., Private Communication. (1971)

3. R. K. Schulz et al., "Some Experiments on the Decontamination of Soils Containing Strontium 90," Higardia. (1959) 